\title{
Health Care Workers' Knowledge, Attitude, and Practice About Chronic Pain Management, Shiraz, Iran
}

\author{
Raziyeh Kheshti, ${ }^{1}$ Soha Namazi, ${ }^{1, *}$ Manoosh Mehrabi, ${ }^{2}$ and Dena Firouzabadi ${ }^{1}$ \\ ${ }^{1}$ Department of Clinical Pharmacy, School of Pharmacy, Shiraz University of Medical Sciences, Shiraz, Iran \\ ${ }^{2}$ Center of Excellence for E-learning in Medical Sciences, Shiraz University of Medical Sciences, Shiraz, Iran \\ "Corresponding author: Soha Namazi, Department of Clinical Pharmacy, School of Pharmacy, Shiraz University of Medical Sciences, Shiraz, Iran. Tel: +98-7132424127, E-mail: \\ namazisoha@yahoo.com, snamazi@sums.ac.ir
}

Received 2016 March 12; Revised 2016 May 07; Accepted 2016 June 06.

\begin{abstract}
Background: Pain can adversely affect every aspect of a patient's daily activity, and consequently, it has a great influence on the quality of life. Studies have shown that health care professionals have little knowledge of and inadequate attitudes toward the assessment of pain and its treatment with analgesics.

Objectives: This cross-sectional study was designed to evaluate the knowledge, attitudes, and practice of health care professionals regarding chronic pain management. It was carried out in six different educational hospitals affiliated with Shiraz University of Medical Sciences in Shiraz, Iran.

Patients and Methods: Participants were given a questionnaire containing 46 questions and demographic characteristics to fill out independently. In total, 213 health care professionals (114 nurses and 99 medical residents) volunteered to take part in this study. In order to ease further analysis, the questions were grouped into three categories: narcotic drugs, non-narcotic drugs, and nondrug-related questions.

Results: The mean correct response rate was $43.13 \% \pm 11.10$. Medical residents scored $51.23 \% \pm 9.02 \%$ and nurses $36.10 \% \pm 7.31 \%(P<$ 0.001). There was no statistically significant relation between field of specialty and the mean scores of medical residents. Narcotic drug questions received the lowest (39.02\%) and non-narcotic drug questions received the highest (57.32\%) percentages of correct responses. Only 9.3\% of participants believed that they had received adequate education about pain and its management.

Conclusions: The findings of this study support concern about inadequate knowledge, attitudes, and practice regarding chronic pain management. We believe that further education and practical training will be needed for adequate pain management.
\end{abstract}

Keywords: Pain Management, Knowledge, Attitude, Practice

\section{Background}

Pain was a frequent chief complaint for adults who referred to emergency departments in 2006 , and pain severity was stated as moderate to severe by $45.0 \%$ of cases in these emergency departments (1). The international association for the study of pain has defined pain as an unpleasant sensory and emotional experience associated with actual or potential tissue damage or described in terms of such damage (2).

Despite extensive progress in the scientific understanding of pain over the last decade, pain in health institutions and in the community is still high. Therefore, many patients suffer from unnecessary and avoidable pain (3-5). One obvious example is low back pain, which requires several modalities for appropriate management for most patients (6).

\subsection{Literature Review}

Studies have shown that health care professionals have little knowledge of and inadequate attitudes toward the assessment of pain and its treatment with analgesics. These deficiencies include misconceptions about pain assessment and the erroneous belief that patients exaggerate their pain, inappropriate beliefs about drug tolerance and addiction, inadequate knowledge of analgesic drugs pharmacology, and a difficulty in assessing pain in children (710).

To our knowledge, limited studies have been published regarding pain knowledge in Iran $(11,12)$. One study was conducted among nursing students and indicated that Iranian nursing students seem to have the least knowledge of pain assessment and management in comparison with international standards (12). But a second study showed that anesthesiology residents and faculty members had desirable beliefs about pain management (11). We were unable to find any published Iranian studies focusing on both 
nurses' and physicians' knowledge, attitudes, and practice with respect to chronic pain.

The treatment of pain should encompass a multidisciplinary approach and should ideally involve the evaluation and treatment of patients by the health care team, from physicians to nurses (13).

\section{Objectives}

The aims of this study were the following: 1) to evaluate the knowledge, attitudes, and practice of physicians and nurses with respect to chronic pain management in the educational hospitals affiliated with Shiraz University of Medical Sciences (SUMS), Shiraz, Iran; and 2) to identify areas where deficiencies exist.

\section{Patients and Methods}

This cross-sectional study was carried out in six different educational hospitals affiliated with SUMS. A questionnaire was given to medical residents and nurses of different clinical wards of the hospitals including rehabilitation, internal medicine, cardiology, psychiatry, pediatrics, and neurology, and the participants were asked to fill them out independently. In Iran, the residency program starts after seven years of a general physicians program. The duration of the residency program is four years, with residents divided into first-, second-, third-, and fourth-year residents based on their education and practice. A questionnaire comprising 46 items measured the participants' knowledge, attitudes, and practice regarding management of chronic pain (Table 1 ). The questionnaire included 23 truefalse questions, 9 multiple-choice questions, 12 questions using a Likert scale, and 2 case-study questions. Thirty-six questions were adopted from questionnaires used in similar studies (7-10, 14-16) and modified afterwards, and 10 questions (L2, T3, T4, T7, T19, T23, M6, M7, M8, and M9) were designed through the cooperation of the clinical pharmacy department and the center of excellence for electronic learning at SUMS. The questionnaire also consisted of demographic items and job characteristics including age, gender, marital status, field of specialization, year of residency, clinical ward, years of nursing experience, attendance in courses dealing with pain, beliefs regarding selfknowledge about pain, and the efficacy of pain management in their clinical wards.

The content validity of the questionnaire was determined by a group of experts consisting of a rehabilitation specialist, a clinical pharmacy specialist, and an anesthesiologist with a pain management fellowship. The internal reliability of the questionnaire was acceptable (Cronbach's alpha $=0.76$ ).
In analyzing the questionnaire, we did not distinguish among questions that quantified the extent of knowledge, attitudes, or practice separately with respect to pain management. This was due to the overlap of the aforementioned concepts. In order to allow better analysis of the questions, they were grouped into three categories: narcotic drug questions (18 items), non-narcotic drug questions (10 items), and non-drug-related questions (20 items). Two questions (T20, M4) were similar with respect to both the narcotic and non-narcotic drug items.

Correctly answered questions were assigned a score of 1. Incorrectly answered questions and those not answered were assigned a score of 0 . The total score was calculated for each participant by adding up the scores for each question.

Continuous variables were shown as mean \pm SD, and categorical values were reported as percentages. An independent sample t-test was used to compare the mean percentage of correct answers between nurses and medical residents. The Chi-square and Fisher exact tests were performed for comparison between categorical variables and the groups. The Pearson correlation test was utilized to assess the correlation between the ages of participants and the percentage of correct answers. Correlations between the year of residency, years of nursing experience, and the mean percentages of correct answers were analyzed using the Spearman correlation test. Comparisons were made between continuous variables and groups using one-way ANOVA. A comparison between the means of the percentage of correct answers to narcotic, nonnarcotic, and non-drug-related questions both within subject factors (nurses and medical residents) and between subject factors (nurses and medical residents) was processed by repeated-measure ANOVA. A Kruskal-Wallis test was done to examine the association between the degrees of self-perception of pain knowledge in participants and the average scores they achieved.

The results were analyzed using Statistical Program for Social Sciences (SPSS) version 17.0 for windows. A P-value < 0.05 was considered statistically significant.

\section{Results}

In total, 213 health care professionals (114 nurses and 99 medical residents) volunteered to take part in this study. The demographic and practice characteristics of the participants are presented in Table 2.

Attendance in courses related to pain management was higher in nurses than in medical residents $(14.0 \%$ of nurses and $5.0 \%$ of medical residents, $\mathrm{P}=0.037$ ). There was no relationship between attendance in courses dealing with pain and the mean scores of either medical res- 
Table 2. Demographic and Practice Characteristics of the Participants $(N=213)$

\begin{tabular}{|c|c|}
\hline Characteristics & No. (\%) \\
\hline \multicolumn{2}{|l|}{ Sex } \\
\hline Male & $66(31.0)$ \\
\hline Female & $147(69.0)$ \\
\hline Age $(y)$, mean $\pm S D$ & $30.8 \pm 5.7$ \\
\hline $21-30$ & $124(58.2)$ \\
\hline $31-40$ & $73(34.3)$ \\
\hline $41-50$ & $16(7.5)$ \\
\hline \multicolumn{2}{|l|}{ Marital status } \\
\hline Married & $124(58.2)$ \\
\hline Single & $89(41.8)$ \\
\hline \multicolumn{2}{|l|}{ Specialties of medical residents } \\
\hline Rehabilitation & $12(12.1)$ \\
\hline Internal medicine & $17(17.2)$ \\
\hline Cardiology & $24(24.2)$ \\
\hline Psychiatry & $13(13.1)$ \\
\hline Pediatrics & $19(19.2)$ \\
\hline Neurology & $14(14.1)$ \\
\hline \multicolumn{2}{|l|}{ Nursing experience, $y$} \\
\hline $1-5$ & $70(61.4)$ \\
\hline $6-10$ & $20(17.5)$ \\
\hline$>10$ & $24(21.1)$ \\
\hline \multicolumn{2}{|l|}{ Years of residency } \\
\hline 1 & $25(25.3)$ \\
\hline 2 & $32(32.3)$ \\
\hline 3 & $30(30.3)$ \\
\hline 4 & $12(12.1)$ \\
\hline \multicolumn{2}{|l|}{ Attendance in courses dealing with pain } \\
\hline Only in initial education process & $192(90.1)$ \\
\hline$<5$ hours complementary education & $6(2.8)$ \\
\hline 5 -10 hours complementary education & $8(3.8)$ \\
\hline$>10$ hours complementary education & $7(3.3)$ \\
\hline
\end{tabular}

idents or nurses (medical residents: $\mathrm{P}=0.103$, nurses: $\mathrm{P}=0.491$ ). Additionally, $37.6 \%$ of participants believed that they should receive initial education concerning pain management, $53.1 \%$ of them felt that they needed extra courses dealing with pain management, and 9.3\% believed that they had received adequate education about pain and its management. But the degree of self-perception of pain knowledge in medical residents and nurses was not related to the average scores they achieved (medical residents: $\mathrm{P}=$
0.769, nurses: $\mathrm{P}=0.113$ ).

The mean percentage of correct answers was $43.13 \pm$ $11.10 \%$, consisting of $51.23 \pm 9.02 \%$ for medical residents and $36.10 \pm 7.31 \%$ for nurses $(\mathrm{P}<0.001)$. There was no significant difference between the two sexes in the two studied groups (nurses: $\mathrm{P}=0.58$, medical residents: $\mathrm{P}=0.45$ ).

There was no correlation between the ages and mean scores of either medical residents or nurses (medical residents: $\mathrm{P}=0.214, \mathrm{r}=-0.13$ and nurses: $\mathrm{P}=0.983, \mathrm{r}=0.00$ ). However, the residency year of medical residents was significantly correlated $(\mathrm{P}=0.002, \mathrm{r}=0.30)$ with their scores.

Although no significant association between field of specialty and the mean scores of medical residents ( $\mathrm{P}=$ 0.692) was observed, a neurology resident received the highest (54.2\%) and a psychiatry resident received the lowest (49.8\%) mean scores.

The individual percentages of correct answers to all 46 items are presented in Table 1 . The item with the highest percentage of correct answers (89.7\%) was number 15 of the true-false questions (The parents' presence usually alleviates the pain experienced by children. [The correct answer was true.]). The item with the lowest percentage of correct answers (1.9\%) was number 5 of the multiplechoice questions (percentage of patients who over-report their pain level [The correct answer was 0.0\%.]). Results showed that medical residents scored significantly higher than nurses with respect to this item (medical residents: $4.0 \%$ vs. nurses: $0.0 \%, P=0.045)$. Among residents, only $21.1 \%$ of pediatricians answered this question correctly, and the correct percentages of the other specialties were $0.0 \%$.

Among participants, $62.4 \%$ incorrectly believed that opioids were not good drugs and that it was better for patients to tolerate pain as much as possible; $63.6 \%$ of medical residents and $95.6 \%$ of nurses overestimated the likelihood of addiction following narcotic utilization for pain management (addiction rate $>1.00 \%$ ). The percentage of correct answers from medical residents was significantly higher than from nurses with respect to this item $(\mathrm{P}<$ 0.001).

Of the respondents, $65.3 \%$ (41.4\% of medical residents and $86.0 \%$ of nurses) incorrectly believed that the use of a placebo was a useful test for determining the existence of pain $(\mathrm{P}<0.001)$.

The percentages of correct answers from medical residents and nurses to narcotic drug questions, non-narcotic drug questions, and non-drug-related questions were calculated separately. Medical residents scored significantly higher than nurses in all three categories of pain control methods (the P-value of all was $\mathrm{P}<0.001$ ). The mean percentages of correct answers regarding field of specialty are shown in Table 3. 
Table 3. The Mean Percentages of Correct Answers to Narcotic, Non-Narcotic, and Non-Drug-Related Questions by Medical Residents Regarding Field of Specialty ( $\mathrm{N}=$ 99)

\begin{tabular}{|c|c|c|}
\hline Category & Mean $\% \pm$ SD & P Value \\
\hline Narcotic questions & & 0.882 \\
\hline Rehabilitation & $43.06 \pm 15.91$ & \\
\hline Internal medicine & $46.73 \pm 13.47$ & \\
\hline Cardiology & $48.15 \pm 15.51$ & \\
\hline Psychiatry & $44.02 \pm 13.31$ & \\
\hline Pediatrics & $47.66 \pm 14.26$ & \\
\hline Neurology & $44.44 \pm 13.07$ & \\
\hline Total & $46.13 \pm 14.14$ & \\
\hline Non-Narcotic questions & & 0.008 \\
\hline Rehabilitation & $76.67 \pm 12.31$ & \\
\hline Internal medicine & $71.76 \pm 13.08$ & \\
\hline Cardiology & $74.17 \pm 10.06$ & \\
\hline Psychiatry & $63.85 \pm 14.46$ & \\
\hline Pediatrics & $63.61 \pm 17.34$ & \\
\hline Neurology & $78.57 \pm 15.12$ & \\
\hline Total & $71.21 \pm 14.80$ & \\
\hline Non-Drug-Related questions & & 0.017 \\
\hline Rehabilitation & $52.50 \pm 11.18$ & \\
\hline Internal medicine & $43.53 \pm 10.42$ & \\
\hline Cardiology & $41.88 \pm 8.32$ & \\
\hline Psychiatry & $49.23 \pm 7.60$ & \\
\hline Pediatrics & $49.74 \pm 15.41$ & \\
\hline Neurology & $51.79 \pm 9.73$ & \\
\hline Total & $47.32 \pm 11.35$ & \\
\hline
\end{tabular}

\section{Discussion}

The current study examined the knowledge, attitudes, and practice of a sample of medical residents and nurses regarding chronic pain management in Shiraz, Iran. The overall percentage of correct answers was $43.1 \%$ (residents: 51.2\%, nurses: $36.1 \%, \mathrm{P}<0.001)$. Compared with the studies of Visentin et al. (61\%) (17) and Van Niekerk et al. (72\%) (18), the present study showed a lower correct answer rate. Visentin et al.'s study was conducted on 669 nurses and 225 physicians in Italy, and Van Niekerk et al.'s study was done on 1015 Tasmanian nurses. However, the results of our study did not greatly differ from the results published by Rahimi-Madiseh et al. (12), who conducted a study in two Iranian nursing schools (Shahrekord and Tehran) in Iran, using a questionnaire with 36 items and 2 case studies. In that study, out of 146 nursing students, the percentage of correct answers obtained was 37\%. A further comparison with this questionnaire was not possible, because the questionnaire was different from ours in regards to the type and number of questions. On the other hand, the percent of correct answers from the nurses in our study (36.1\%) is similar to that in Yildirim et al.'s study (35.4\%), conducted on 68 nurses in Turkey (9).

In our survey, there was a statistically significant difference between the mean percentages of correct answers of the different professional groups (medical residents: $51.2 \%$ vs. nurses: $36.1 \%, \mathrm{P}<0.001$ ). This difference was also noticed by Zanolin et al. (10) and Visentin et al. (17). Prior to analyzing the results, we did expect the medical residents to be more knowledgeable than nurses, because physicians are responsible for diagnosing the causes of pain and prescribing the appropriate drugs.

After analyzing the answers to individual items, question T15 showed the highest percentage of correct answers (89.7\%); this result showed that most of the respondents correctly believed that in the management of pain in children, medication is not the only method by which to alleviate it. However, the lowest percentage $(1.9 \%)$ of correct answers referred to question M5, where most participants (98.1\%) incorrectly believed that patients exaggerated their pain. Surprisingly, all of the nurses answered this question incorrectly. Special attention should be given to this matter, because members of medical staff who believe that patients are over-reporting their pain may be less likely to apply the best pain management strategies. This finding was similar to those of several other surveys $(9,19,20)$.

Unlike some earlier surveys, our study showed no difference in the pain management knowledge of nurses from oncology units compared to nurses from other clinical wards. Previous studies $(21,22)$ may have utilized survey tools containing a disproportionate number of cancerrelated items compared to other pain management areas, leading to the better answers of oncology nurses. However, our study used a questionnaire that contained almost a balanced number of questions concerning nonpharmacology, pharmacology, addiction, assessment, and patient-related variables. Overall, our study did not show a significant difference between nurses in different clinical units. Recently, one study reported that no significant difference was seen among nurses working in three different wards (23).

We learned that there was no relationship between years of nursing experience and the mean score of nurses' correct answers. This finding was in contrast to the findings of Lui et al. (24), Lai et al. (25), and Tse et al. (26). Other studies confirmed the importance of university courses and also of continuing education to improve the level of knowledge and the attitudes of nurses regarding pain 
management $(27,28)$.

The findings of the previous studies $(10,17)$ reported that medical specialty had a profound effect on the knowledge of and attitudes toward pain management. In contrast to these findings, our results showed that the difference in scores between medical residents with different specialties was not significant. One of the most important reasons for these results is found in the medical educational program at SUMS; pain management education is not related to residents' fields of residency.

There was no correlation between age and the mean scores of either medical residents or nurses. These results were in contrast to the findings of Ali et al. (29) and Salantera et al. (8), where both studies found that the older the respondents, the higher the scores. But Latina et al supported our finding (23).

Nurses and medical residents who were confident in their knowledge (having a higher degree of selfperception) had no higher scores in pain management than did those who were not. This confidence may lead to inadequate treatment and may prevent these medical staff from improving their knowledge about pain. The findings of Park et al.'s study (30), performed on 1204 South Korean physicians, were not confirmed by our data.

Among participants, 9.4\% and 28.6\%, respectively, had correct responses to questions $\mathrm{C} 1$ and $\mathrm{C} 2$. In a previous study, it was reported that nurses were most likely to accept the patient's pain complaint if the patient was grimacing, had elevated vital signs, or was elderly (31). Yildirim et al. conducted a study on 68 Turkish oncology nurses, reporting that 19.1\% (for C1) and 35.3\% (for C2) of nurses gave a correct response to the same questions (9).

Our results showed that narcotic questions produced the lowest percentage of correct answers followed by nondrug-related and then non-narcotic questions. Only $19.2 \%$ of the respondents correctly marked the likelihood of addiction to narcotic drugs as $<1.0 \%$. This result was inconsistent with the results of two other studies (Fife et al., 27\% (32), and Rahimi-Madiseh et al., 64.9\% (12)). Furthermore, because of the excessive fear of tolerance and addiction, $62.4 \%$ of our participants incorrectly believed that narcotics were not good drugs and that patients had better bear the pain as much as possible. This result was quite different from Yildirim et al.'s (9) and Ferrell et al.'s studies (33), which showed, respectively, that $61.8 \%$ and $98.0 \%$ of respondents correctly believed that patients should not have to bear pain.

Among our respondents, 53.3\% did not prescribe narcotics to patients with a history of substance abuse (question T8). However, this behavior is incorrect, because patients with a history of substance abuse can develop medical conditions that cause severe pain, and there is some evidence that such patients may not be at high risk for developing repeated psychological dependency on narcotic drugs (34). Yildirim et al. reported that only $16.2 \%$ of nurses gave correct responses to this question (9). But in another study performed with 2710 Tasmanian nurses, it was reported that $64.9 \%$ of participants gave correct responses to this question (T8) (18).

Similar to several earlier studies $(9,17,19)$, knowledge deficits were found in our studied population regarding the use of placebos. Nearly $65.3 \%$ of the participants believed that injection of a placebo (sterile water for injection) was a useful test for determining the reality of pain reported by patients. Our result was several times higher than the results of the studies of Van Niekerk et al. (19.8\%) (18) and Yildirim et al. (8.8\%) (9). As mentioned above, these results confirmed that the health care workers in our study did not trust patients in reporting their severity of pain.

According to the previous surveys (31, 35), selfreporting of pain is the single most reliable indicator for pain assessment. The elevation of vital signs has not been recommended as an alternative to self-reporting. It is notable that in our study, most (77.9\%) of the medical staff (medical residents: $67.7 \%$ and nurses: $86.8 \%$ ) incorrectly believed that observable changes in vital signs were reliable indicators of pain intensity. This negative attitude was significantly higher in nurses than in medical residents ( $P$ $=0.001)$.

In general, the discrepancy between our study and other studies could be due to the type of studied population as well as the type of questionnaire. Although $78.3 \%$ of our questions were essentially the same as those in other studies, the remaining $21.7 \%$ difference between questionnaires could impact the final results. Also, this study was conducted in a university hospital with no independent department of pain; therefore, there was no wellorganized protocol for pain management. As shown in the results, the pain management method was decided based on the health provider's personal experience. Such a practice can also be seen in other clinical settings in the world $(36,37)$.

There are some limitations present in this study. First, the sample was collected from only one medical science university, and it is probably improper to generalize the findings to the whole population of Iranian health care providers. Second, our sample represents a much more sophisticated and academic group of clinicians compared to average clinicians. It is quite possible that nurses and physicians in smaller cities might have even less knowledge and more conservative practices and attitudes toward pain management. Third, the questionnaire was designed for this survey and contained some questions that have not been tested in other populations. Also, since pain 
is a very broad-spectrum subject, it is possible that some areas of chronic pain management may remain uncovered.

\subsection{Conclusions}

As a final point, the main finding of this study showed that there was a significant deficit in knowledge, attitudes, and practice regarding pain and its management in the sample of medical residents and nurses who were surveyed. There is an urgent necessity for educational programs and the use of standard treatment guidelines for pain management to help medical staff achieve improved knowledge, attitudes, and practices in order to enhance the quality of life of patients and save the costs of pain management.

\section{Footnotes}

Authors' Contribution: Study concept and design, Soha Namazi; Raziyeh Kheshti and Manoosh Mehrabi; analysis and interpretation of data, Raziyeh Kheshti and Dena Firouzabadi; drafting of the manuscript, Raziyeh Kheshti; critical revision of the manuscript for important intellectual content, Soha Namazi, Manoosh Mehrabi, Dena Firouzabadi; statistical analysis, Raziyeh Kheshti and Soha Namazi.

Conflicts of Interest: All authors had no conflict of interest.

Funding/Support: This study was financially supported by Shiraz University of Medical Sciences.

\section{References}

1. Centre for Disease Control and Prevention . Inpatient Surgury: National centre for health statistics. FastStats. 2010.

2. International Association for the Study of Pain . IASP proposed toxonomy search. 2008

3. Costantini M, Viterbori P, Flego G. Prevalence of pain in Italian hospitals: results of a regional cross-sectional survey. J Pain Symptom Manage. 2002;23(3):221-30. [PubMed: 11888720].

4. Trentin L, Visentin M, de Marco R, Zandolin E. Prevalence of pain in public hospital: correlation between patients and caregivers. headache pain. 2001;2(2):73-8.

5. Moceri JT, Drevdahl DJ. Nurses' knowledge and attitudes toward pain in the emergency department. J Emerg Nurs. 2014;40(1):6-12. doi: 10.1016/j.jen.2012.04.014. [PubMed: 22841012].

6. Patel VB, Wasserman R, Imani F. Interventional Therapies for Chronic Low Back Pain: A Focused Review (Efficacy and Outcomes). Anesth Pain Med. 2015;5(4):e29716. doi: 10.5812/aapm.29716. [PubMed: 26484298].

7. Ger LP, Ho ST, Wang JJ. Physicians' knowledge and attitudes toward the use of analgesics for cancer pain management: a survey of two medical centers in Taiwan. J Pain Symptom Manage. 2000;20(5):33544. [PubMed: 11068155].

8. Salantera S, Lauri S, Salmi TT, Helenius H. Nurses' knowledge about pharmacological and nonpharmacological pain management in children. J Pain Symptom Manage. 1999;18(4):289-99. [PubMed: 10534969].
9. Yildirim YK, Cicek F, Uyar M. Knowledge and attitudes of Turkish oncology nurses about cancer pain management. Pain Manag Nurs. 2008;9(1):17-25. doi:10.1016/j.pmn.2007.09.002. [PubMed:18313586].

10. Zanolin ME, Visentin M, Trentin L, Saiani L, Brugnolli A, Grassi M. A questionnaire to evaluate the knowledge and attitudes of health care providers on pain. J Pain Symptom Manage. 2007;33(6):727-36. doi: 10.1016/j.jpainsymman.2006.09.032. [PubMed: 17531913].

11. Panah Khahi M, Khajavi MR, Nadjafi A, Moharari RS, Imani F, Rahimi I. Attitudes of anesthesiology residents and faculty members towards pain management. Middle East J Anaesthesiol. 2012;21(4):521-8. [PubMed: 23327024].

12. Rahimi-Madiseh M, Tavakol M, Dennick R. A quantitative study of Iranian nursing students' knowledge and attitudes towards pain implication for education. Int J Nurs Pract. 2010;16(5):478-83. doi: 10.1111/j.1440-172X.2010.01872.x. [PubMed: 20854345].

13. Imani F, Safari S. "Pain Relief is an Essential Human Right", We Should be Concerned about It. Anesth Pain Med. 2011;1(2):55-7. doi: 10.5812/kowsar.22287523.2306. [PubMed: 25729655].

14. Chiang LC, Chen HJ, Huang L. Student nurses' knowledge, attitudes, and self-efficacy of children's pain management: evaluation of an education program in Taiwan. J Pain Symptom Manage. 2006;32(1):82-9. doi: 10.1016/j.jpainsymman.2006.01.011. [PubMed: 16824988].

15. Furstenberg CT, Ahles TA, Whedon MB, Pierce KL, Dolan M, Roberts $\mathrm{L}$, et al. Knowledge and attitudes of health-care providers toward cancer pain management: a comparison of physicians, nurses, and pharmacists in the state of New Hampshire. J Pain Symptom Manage. 1998;15(6):335-49. [PubMed: 9670634].

16. Sloman R, Ahern M, Wright A, Brown L. Nurses' knowledge of pain in the elderly. J Pain Symptom Manage. 2001;21(4):317-22. [PubMed: 11312046].

17. Visentin M, Trentin L, de Marco R, Zanolin E. Knowledge and attitudes of Italian medical staff towards the approach and treatment of patients in pain. J Pain Symptom Manage. 2001;22(5):925-30. [PubMed 11728795].

18. Van Niekerk LM, Martin F. Tasmanian nurses' knowledge of pain management. Int J Nurs Stud. 2001;38(2):141-52. [PubMed:11223055].

19. Bernardi M, Catania G, Lambert A, Tridello G, Luzzani M. Knowledge and attitudes about cancer pain management: a national survey of Italian oncology nurses. Eur J Oncol Nurs. 2007;11(3):272-9. doi 10.1016/j.ejon.2006.09.003. [PubMed: 17112781].

20. Brown ST, Bowman JM, Eason FR. Assessment of nurses' attitudes and knowledge regarding pain management. J Contin Educ Nurs. 1999;30(3):132-9. [PubMed:10640072].

21. Brunier G, Carson MG, Harrison DE. What do nurses know and believe about patients with pain? Results of a hospital survey. J Pain Symptom Manage. 1995;10(6):436-45. [PubMed: 7561226].

22. McCaffery M, Ferrell BR. Nurses' knowledge about cancer pain: a survey of five countries. J Pain Symptom Manage. 1995;10(5):356-69. [PubMed: 7673768].

23. Latina R, Mauro L, Mitello L, D’Angelo D, Caputo L, De Marinis MG, et al. Attitude and Knowledge of Pain Management Among Italian Nurses in Hospital Settings. Pain Manag Nurs. 2015;16(6):959-67. doi 10.1016/j.pmn.2015.10.002. [PubMed: 26697820].

24. Lui LY, So WK, Fong DY. Knowledge and attitudes regarding pain management among nurses in Hong Kong medical units. J Clin Nurs. 2008;17(15):2014-21. [PubMed: 18720572].

25. Lai YH, Chen ML, Tsai LY, Lo LH, Wei LL, Hong MY, et al. Are nurses prepared to manage cancer pain? A national survey of nurses knowledge about pain control in Taiwan. J Pain Symptom Manage. 2003;26(5):1016-25. [PubMed: 14585553].

26. Tse MM, Chan BS. Knowledge and attitudes in pain management: Hong Kong nurses' perspective. J Pain Palliat Care Pharmacother. 2004;18(1):47-58. [PubMed: 15148008]. 
27. Kiekkas P, Gardeli P, Bakalis N, Stefanopoulos N, Adamopoulou K, Avdulla C, et al. Predictors of nurses' knowledge and attitudes toward postoperative pain in Greece. Pain Manag Nurs. 2015;16(1):2-10. doi: 10.1016/j.pmn.2014.02.002. [PubMed: 24981120].

28. McNamara MC, Harmon D, Saunders J. Effect of education on knowledge, skills and attitudes around pain. Br J Nurs. 2012;21(16):958. doi 10.12968/bjon.2012.21.16.958. [PubMed: 23123650] 960-4.

29. Ali N, Thomson D. A comparison of the knowledge of chronic pain and its management between final year physiotherapy and medical students. Eur J Pain. 2009;13(1):38-50. doi: 10.1016/j.ejpain.2008.02.005. [PubMed:18434220].

30. Kim MH, Park H, Park EC, Park K. Attitude and knowledge of physicians about cancer pain management: young doctors of South Korea in their early career. Jpn J Clin Oncol. 2011;41(6):783-91. doi: 10.1093/jjco/hyr043. [PubMed: 21502282].

31. McCaffery M, Ferrell BR. Nurses' knowledge of pain assessment and management: how much progress have we made?. J Pain Symptom Manage. 1997;14(3):175-88. [PubMed: 9291704].
32. Fife BL, Irick N, Painter JD. A comparative study of the attitudes of physicians and nurses toward the management of cancer pain.J Pain Symptom Manage. 1993;8(3):132-9. [PubMed: 8326163].

33. Ferrell BR, Dean GE, Grant M, Coluzzi P. An institutional commitment to pain management. J Clin Oncol. 1995;13(9):2158-65. [PubMed: 7666074].

34. Vourakis C. Substance abuse concerns in the treatment of pain. Nurs Clin North Am. 1998;33(1):47-60. [PubMed: 9478905].

35. McCaffery M, Ferrell BR, Pasero C. Nurses' personal opinions about patients' pain and their effect on recorded assessments and titration of opioid doses. Pain Manag Nurs. 2000;1(3):79-87. doi: 10.1053/jpmn.2000.9295. [PubMed: 11706463].

36. Green CR, Anderson KO, Baker TA, Campbell LC, Decker S, Fillingim $\mathrm{RB}$, et al. The unequal burden of pain: confronting racial and ethnic disparities in pain. Pain Med. 2003;4(3):277-94. [PubMed: 12974827].

37. Institute of Medicine . Relieving Pain in America: A Blueprint for Transforming Prevention, Care, Education, and Research:. National academies press; 2011 
Table 1. Questions and Percent of Correct Answers to Them

\begin{tabular}{l} 
Item Question \\
\hline Case studies \\
C1: A 54-year-old woman, with a known case of rheumatoid arthritis (RA) from 6 years ago, is hospitalized in the \\
rheumatology ward for pain and inflammation control. As you enter her room, she smiles at you and continues talking \\
and joking with her visitor. Your assessment reveals the following information: $\mathrm{BP}=120 / 80 ; \mathrm{HR}=80 ; \mathrm{R}=18$. On a scale of 0 \\
to 10 ( $0=$ no pain/discomfort and $10=$ worst pain/discomfort $)$, she rates her own pain a score of 8 . On the patient's record, \\
you must mark her pain on the scale below. Circle the number that represents your assessment of her pain.
\end{tabular}

$$
10|9| 8|7| 6|5| 4|3| 2|1| 0
$$

Worst pain No pain

C2: A 54-year-old woman, with a known case of rheumatoid arthritis (RA) from 6 years ago, is hospitalized in the rheumatology ward for pain and inflammation control. As you enter her room, she is lying quietly in bed and grimacing. Your assessment reveals the following information: $\mathrm{BP}=120 / 80 ; \mathrm{HR}=80 ; \mathrm{R}=18$. On a scale of 0 to $10(0=$ no pain/discomfort and $10=$ worst pain/discomfort), she rates her own pain a score of 8 . On the patient's record, you must mark her pain on the scale below. Circle the number that represents your assessment of her pain.

\section{$10|9| 8|7| 6|5| 4|3| 2|1| 0$}

Worst pain No pain

\section{Likert Scale Questions}

L1- Giving a narcotic on a regular schedule is preferred over a PRN schedule for continuous pain.

L2- Long-time use of Tramadol causes fewer harmful effects (such as tolerance, addiction, and psychological dependence) than other opioid drugs.

L3- It may often be useful to give a placebo to a patient in pain to assess whether he/she is genuinely in pain.

L4-Administering opioids in a PRN dosing schedule can decrease the harmful effects of opioids such as tolerance and addiction.

L5- Most patients prefer parenteral administration of medication rather than its oral form for pain management.

L6- Parenteral administration is more efficacious than oral administration in pain management.

L7- A patient's report of pain is as reliable as his/her report of nausea.

L8- The dosages of opioids that patients receive should be much lower than the required dosage, for prevention of drug tolerance.

L9- When I prescribe opioids, I would insinuate to patients or their relatives that opioids are not good drugs and that they had better bear the pain as much as possible.

L10- The most suitable dose of morphine for a patient in pain is a dose that best controls the symptoms; there is no maximum dose (i.e., a level that must not be exceeded) for morphine.

L11- For patients with severe nausea and vomiting, abdomen distention, and/or severe constipation, I would prescribe opioids infrequently or with lower dosage.

L12-It is a patient's right to expect total pain relief as a consequence of treatment.

Agree

Agree

Agree

Disagree

Disagree

Disagree

Disagree

16.4

Agree

20.2

32.9

Disagree 21.6

Disagree

3.7 .6

Agree

24.9

Disagree

10.8

Agree

54.0

\section{True-False Questions}

T1- Patients may sleep in spite of severe pain.

True

49.3

T2- Comparable stimuli in different people produce the same intensity of pain.

T3- Diclofenac and Celecoxib have a synergistic effect as pain killers.

T4- Maximum daily dosage of acetaminophen for a patient with liver failure is $4 \mathrm{~g}$.

T5- Non drug interventions (e.g., heat, music, images) are effective for mild to moderate pain control but not for more severe pain.

T6- The world health organization (WHO) pain ladder suggests using single analgesic agents rather than combining classes of drugs (e.g., combining an opioid with a non-steroidal agent).

T7- For a patient with a history of asthma and aspirin sensitivity, the best NSAID is naproxen.

False

83.1

False

54.9

False

61.0

False

15.0

False

40.4

T8- Patients with a history of substance abuse should not be given opioids for pain, because they are at high risk for repeated addiction.

T9- Elderly patients cannot tolerate opioids for pain relief.

45.1

22.1

4.7

6

4


T10- Observable changes in vital signs must be relied upon to verify a patient's statement that he/she has severe pain.

\begin{tabular}{|ll}
\hline False & 22.1 \\
\hline False & 56.8 \\
\hline True & 37.1 \\
\hline False & 58.2 \\
\hline True & 78.4 \\
\hline True & 89.7 \\
\hline False & 74.2 \\
\hline True & 75.6 \\
\hline False & 28.6 \\
\hline True & 86.9 \\
\hline True & 64.3 \\
\hline False & 57.7 \\
\hline False & 21.1 \\
\hline True & 56.3 \\
\hline
\end{tabular}

T11- Children less than 11 years of age cannot report pain with reliability, and therefore the clinician should rely on the parents' assessment of the child's pain intensity.

T12- Based on his or her religious beliefs, a patient may think that pain and suffering is necessary.

T13- Children cannot tolerate opioids for pain relief.

T14- 80\% of pain can be relieved by appropriate treatment with pharmacological pain relievers.

T15-The parent's presence usually alleviates the pain experienced by children.

T16- Pain medication is equally effective whether given before the onset of pain or when the patient is already experiencing pain.

T17- Naloxone can treat respiratory depression caused by opioids.

T18- If a patient reports that a narcotic is causing, euphoria she/he should be given a lower dose of the analgesic.

T19-The drug of choice for prevention of NSAID-induced peptic ulcer disease is Omeprazole.

T20- NSAIDs cannot increase the respiratory depression of opioids.

T21-Sedation is an effective way of eliminating pain in children.

T22- Elderly people experience pain with less intensity than young adults.

T23-Capsaicin is the best topical pain-relieving drug.

M1- The incidence of addiction as a result of the legitimate prescription of narcotic pain-relieving drugs is:

b. $10 \%-50 \%$

c. $1 \%-10 \%$

d. $<1 \%$

M2-When a patient requests increasing amounts of analgesic to control pain, this usually indicates:

a. The patient is psychologically dependent.

b. The patient is experiencing increased pain.

c. The patient has developed a tolerance to the drug.

$\mathrm{d}$. The patient is addicted.

M3- The recommended route of administration of opioid analgesics to patients with prolonged pain is

a. Oral

b. IV

c. IM

d. On patient's request

M4- Which of the following drugs are useful for management of cancer pain?

d

$50.2 \%$

a. Morphine

b. Ibuprofen

c. Amitriptyline

d. All of the above

M5- In your opinion, what is the percentage of patients who over-report the amount of pain they have?

a. $>50 \%$

b. $20 \%-50 \%$

c. $1 \%-20 \%$

d. $0 \%$

M6- Which of the following medications is suitable for pain relief in a 10-month-old child with mild pain (weight $=12 \mathrm{~kg}$ )?

C

$57.3 \%$

a. Diclofenac suppository $100 \mathrm{mg}$ q6 $\mathrm{h}$ 
b. Naproxen suspension $125 \mathrm{mg}$ q12 h

c. Ibuprofen syrup $120 \mathrm{mg} \mathrm{q} 4 \mathrm{~h}$

d. Acetaminophen suppository $325 \mathrm{mg} \mathrm{q} 6 \mathrm{~h}$

M7- Which of the following medications is considered the drug of choice for the treatment of post-herpetic neuralgia?

a. Acetaminophen $500 \mathrm{mg}$ QID

b. Naproxen 500 mg TID

c. Gabapentin $300 \mathrm{mg}$ TID

d. Tramadol $100 \mathrm{mg}$ QID

M8- The patient is a known case of rheumatoid arthritis from the past 5 years. She was admitted to CCU with the

$34.7 \%$

impression of acute coronary syndrome. According to her drug history, she received naproxen $500 \mathrm{mg}$ TID for joint pain relief. Which analgesic is the best selection for her at this time?

a. Naproxen $500 \mathrm{mg}$ TID

b. Decrease the dose of Naproxen; $500 \mathrm{mg}$ BID

c. Discontinue Naproxen and alternate Acetaminophen $500 \mathrm{mg}$ QID

d. Alternate Naproxen with Celecoxib 100 mg BID

M9- The patient is a 42-year-old man who is undergoing chemotherapy treatment for metastatic cancer. In order to control

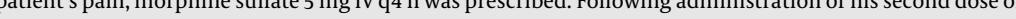

morphine sulfate, he presented erythema, itching, and burning. Which strategy is the best approach to control the

symptoms of allergic reaction to morphine sulfate?

a. Discontinue IV morphine sulfate and use Meperidine $50 \mathrm{mg} \mathrm{q} 4 \mathrm{~h}$

b. Discontinue IV morphine sulfate and use oral morphine $15 \mathrm{mg} \mathrm{q} 4 \mathrm{~h}$

c. Co-administer Hydroxyzine tab 25 - $50 \mathrm{mg}$

d. Dilution of morphine sulfate with normal saline and administering through slow IV infusion. 